\title{
Does the Suitability of National Culture Matters in the Adoption of Six Sigma?
}

\author{
Ahsan Qamar*, Saqib Muneer, Ahmad Jusoh, Halimah Idris \\ Faculty of Management and Human Resource Development, Universiti Teknologi Malaysia, Johor Malaysia \\ *ahsan_qkhan@yahoo.com
}

\begin{abstract}
The concept and methodology of Six Sigma was developed by the American companies within the local culture of America. Therefore it is grounded on the standards, ethics and behaviours represented by America. The present study proposes that implementing Six Sigma in other countries with different cultures, norms and behaviours may have adjustment problems, as the required culture, values and behaviours for Six Sigma do not match with the local cultures of countries. A conceptual model is proposed which would utilize the Hofstede's cultural dimensions to determine the effect of national culture at each phase of Six Sigma process.
\end{abstract}

Keywords: National Culture, Six Sigma, Hofstede Cultural Dimensions,

\section{Introduction}

The objective of the Six Sigma methodology is the improvement of quality. This methodology has been used by organizations worldwide successfully. Most of the successful global companies of US e.g. Hewlett Packard, General Electric, Xerox, Motorola, Allied Signal etc., have achieved a lot of improvements through using this methodology. Besides that many companies from various other countries have also used it successfully to improve their business processes e.g. Toshiba, Samsung and Sony from Japan and Tata Consulting Services from India etc are few of the many companies which have used it. There has been a lot of research on the implementation of Six Sigma in the US based organizations, but there is a lack of literature regarding its implementation in other countries (Hendry \& Nonthaleerak, 2005). The purpose of Six Sigma methodology is to reduce the defects in the business processes until they get completely eliminated. This methodology depends heavily on the data. Through applying this approach quality improvements can be made in business processes related to any of the industries, such as all kinds of manufacturing product and service industries. Even business processes related to finance and accounting can be improved by using this. The target of Six Sigma is to achieve 3.4 or less defects out of a million opportunities, whereas a defect is specified as anything that deviates from the specifications set by customer. There are five steps which have to be done sequentially for achieving this, which are "define measure, analyse, improve and control". These five sequential steps improve different aspects of the process at a time. It is referred to as the guidance-based problem-solving method (McCarty et al., 2005).

The team which works for a Six Sigma project have the following group members. There is a (Black Belt) project leader, some (Green Belt) group members who take care of the daily work of the project, for the problem being focussed there is a process owner, for the outcome of the project there is a local champion who has special interest, as well as there are subject matter specialists who have familiarity with the current project. When all five steps of the Six Sigma process are completed sequentially then the end results are a major and substantial improvement of the process. To implement and continue the Six Sigma process requires high level of human skills. Six sigma methodology was originally developed by Motorola in 1986 in US. This method require that people work as teams in project to achieve improvements in process and this method is totally based on the philosophies and practices of US management. Nevertheless the people living in different cultures and countries have unique characteristics related to their distinct culture, which has an effect on their style of working. So in this perspective the exploration poses lots of challenges as to how six sigma would fit in totally different national cultures to improve the processes of their businesses. In this study we investigate the association between Six Sigma related methods, processes and outcomes and national culture. The particular research question that we deal with here in this study is: 'How does the national culture moderates the influence on the methods, processes and the outcomes related to Six Sigma implementation across different nations? The implementation of Six Sigma has been accomplished worldwide by the multinational enterprises. It is regarded as a strategic approach which enhances the business profitability as well as the operational excellence by effectively utilizing the statistical and non-statistical techniques and tools (Antony and Banuelas, 2002). 


\section{Literature Review}

This study conceptually concentrates on the influence of national culture on the implementation and adoption of Six Sigma. There are two aspects of this study, one is the Six Sigma and the other is a derivation of national culture. This section would start with those two aspects (Six Sigma and national culture); next it would merge the two topics, as is the theme of the paper.

Six Sigma: The basis purpose behind the development of the Six Sigma was to reduce the variation in manufacturing processes and gradually it has developed into a quality improvement programme (e.g. Coronado \& Antony, 2002). The initial applications of Six Sigma were confined and restricted to manufacturing processes only but over the period of time it expanded to other business applications also. It has been applied in health care (e.g. De Brantes \& Galvin, 2001), management of pricing (e.g. Frank, 2003), processes of pricing (e.g. Frank, 2003), federal government (Bigio et al., 2004), city government (e.g. McCarty et al., 2005), software development (e.g. Hong \& Goh, 2003), banking (e.g. Gupta, 2005), supply chain management (e.g. Dasgupta, 2003) and human resource management (e.g. Lanyon, 2003). Some of the other applications not related to manufacturing include claims processing (Lipscomb \& Lewis, 2004), lending processes (Kilbey, 2003), safety (e.g. Revelle, 2004) and training processes (Snee, 2001). Although Six Sigma has been used in so many non-manufacturing areas but Does et al. (2002) has indicated the problems of applying some Six Sigma tools where variation is not so obvious and evident to be precisely measured. Besides Bertels (2000) has pointed out the need to apply other processes than Six Sigma to the administrative and marketing areas.

There has been a research going on to pinpoint the outside factors which can have the negative effect on the successful implementation of Six Sigma processes. There are four types of organizational hindrances that can affect the Six Sigma programme: organizational commitment, individual workload, technical difficulties, stress and political environment (Eckes, 2000). Long term commitment has been proposed as the requirement for the successful Six Sigma (Dale, 2000). Good communication within the corporation offer involves employees which supports efforts towards Six Sigma (Henderson \& Evans, 2000). The utilization of cross-functional teams serves as a base for Six Sigma (Rucker, 2000). Training in terms of creating Black and Green Belt certifications are crucial for the long term success (Hendricks and Kelbaugh, 1998). For creation of motivation among the employees to accept Six Sigma, incentives have a major role (Harry and Schroeder, 2000). Pande et al. (2000) points out towards the significance of including suppliers in the Six Sigma effort. Kaufmann (2000) has pinpointed the critical role the top management can play in developing motivation within the organization to implement Six Sigma.

Researchers have also pinpointed towards the factors that create hindrance in the implementation of Six Sigma. Some researchers are of the view that certain industries or applications are not suitable to adjust to the Six Sigma programme which include the software design process (Binder \& Lawrence, 1997) as well as the product design (Pylipow, 2001). Problems have been identified when data is not sufficient for a process (Gnibus, 2000), when empowerment feature is lacking in corporate culture (e.g. Hutchins, 2000), when training is not adequate (e.g. Hendricks \& Kelbaugh, 1998). Application of Six Sigma in the areas of new product development and research impedes the creativity of employees (White, 2005). Regarding the impact of Six Sigma, there is very limited amount of empirical data (e.g. McAdam \& Lafferty, 2004). Majority of the reports depend on the corporate claims, which may problems in terms of accuracy and reliability. There are some studies which determine the association between the application of Six Sigma and the financial performance. The impact of Six Sigma on the shareholder value is measured (Watson, 2000) and on the quality output (Harry, 2000). Some researchers have measured the affect of Six Sigma on the satisfaction of customers (e.g. Rucker, 2000).

National Culture: In the area of international management, the national culture has gained a lot of significance. But if we talk about culture, then we find that there is no precise definition. One of the first explanation of culture is by Hofstede who defined it as "the collective programming of the mind which distinguishes the members of one group or category of people from another". Hall and Hall (1990) emphasize that culture is like a complex computer program, which directs the actions and reactions of humans in every sphere of life. Hall and Hall further points out that the cultural programs work in their own system and will not work if applied to another system (1990, pp. 3-4). Hence a more comprehensive definition of culture comes out as "is a learned, shared, and interrelated set of specialised behavioural patterns, understandings and adaptations of a like group of people" (Pisani, 2000, p. 25). Newman and Nollen (1996, p. 755) proposes that inside an organisational setup national culture becomes the force of 
organizing the employees, through which they develop their approach to work and the expectations from the organization. Hofstede $(1980,1997)$ proposed five unique measurable dimensions of culture to determine the national culture at the place of work. These five aspects of culture are (1) collectivism/individualism; (2) power distance; (3) masculinity/femininity (4) uncertainty avoidance and (5) long/short term orientation.

Briefly, individualism/collectivism refers to the organizational preference in terms of either individuals or as groups. Power distance refers to the accepted classes in society or at workplace, where people have the belief that some people have to be on the higher hierarchy and the others on the lower. Higher hierarchy has more power than the lower. The environments with low power distance have the participation of all employees of the organization in decision making. Masculinity and femininity has two aspects i.e. the gender preference or equality aspect and the achievement aspect i.e. whether people want high job growth or the balance in life. The uncertainty avoidance corresponds to the acceptance of ambiguity in the organization, in other words it refers to, if the change is easily accepted in the workplace or not. The societies which are high in this aspect have very elaborate rules and regulations. The long term orientation refers to cultures that save today and plan for tomorrow, whereas the short term cultures invest on short term projects.

Compatibility of Six Sigma and National Culture: Crom (2005) investigated the influence of national culture on the implementation of Six Sigma from a US and European context. Especially in the European context he pinpoints that there should be different approaches for Six Sigma implementation in different countries according to the particular culture of the country. According to Crom (2005), the cultures can be categorized based on their level of formality and level of centralization, and using these categorizations, one should devise strategy for the implementation of Six Sigma. For instance trying to develop the Black Belts in Germany where the organisational structures are centralized, would generate resentment among the employees. But that would not be a problem in more individualistic cultures like Sweden and US. The above discussion proves that the national culture has its impact on the implementation of Six Sigma methodology. The national culture is the factor which moderates the philosophy of management, culture of organizations, programmes and tools (Adler, 2002; Hofstede, 1993, 1994; Hofstede \& Hofstede, 2005). Research on the successful implementation of Six Sigma methodology in Chinese companies has found several complications due to the lot of deficiencies prevailing in the local culture which resists the formation of quality improvement culture within the companies (Lee, Wong \& Yeung, 2011). A study based on Six Sigma implementation in Italian companies found that the critical success factors of the application of Six Sigma in an Italian company are the same as are for a US based company, with "Management involvement and commitment" being the most significant aspect (Brun, 2010). The two implementation cases given above indicate that there are national cultural implications on the adoption of Six Sigma i.e. in Italian culture it gets implemented easily but in the case of China with distant cultural standings it becomes difficult.

Conceptual Framework: Conceptual model is developed which make use of the Hofstede cultural dimensions which links the methodology of Six Sigma with the national culture. Our argument is that national culture which is embedded in organizations moderates the implementation of Six Sigma in the organization. The starting point of the model is the organizational problem, and then the next step is the application of Six Sigma to resolve the problem. At this point national culture interacts with the six steps of Six Sigma and this interaction is throughout the lifecycle of the project of solving the problem.

Problem in the Organizational Context: The purpose of six sigma is to solve the problems related to Organizations. There could be a number of problems e.g. minimizing the costs of manufacturing in the organization, cost reduction in services of the company, enhancing the efficiency of a particular process, decreasing the delivery times, decreasing defects in processes of the organization, increasing the revenue of the organization (Sodhi \& Sodhi, 2005).

\section{Six Sigma methodology}

The methodology of Six Sigma comprises of five phases which are define, measure, analyse, improve and the last on is control. The moderating effect of national culture on each of these six phases is discussed below. 


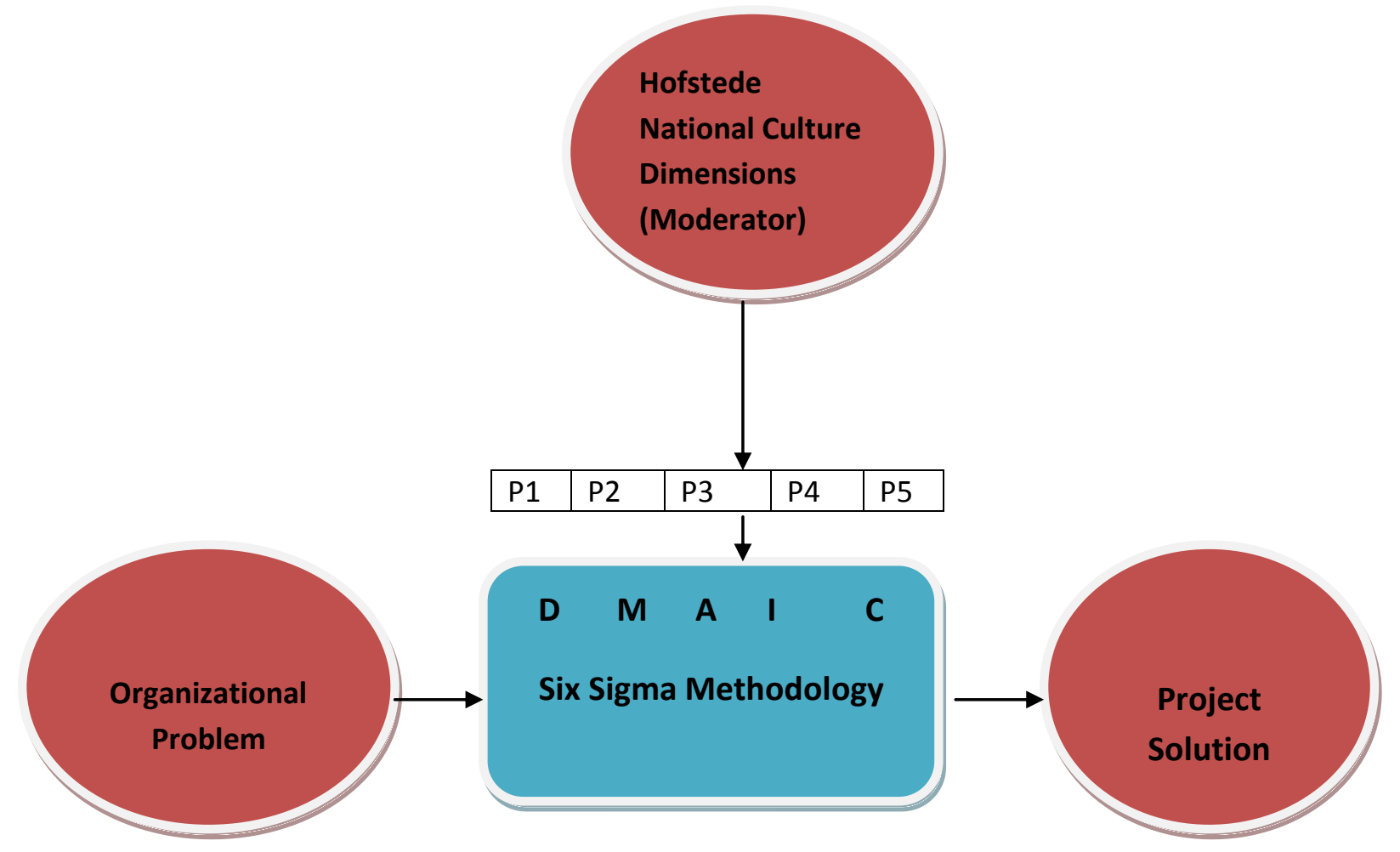

Define: The purpose of this phase is the identification of the defect, which has to be solved through the application of Six Sigma. This is an important phase, as the definition of the defect should also mention the opportunity or benefit the company would get once the problem is fixed, in terms of the organizational resources saved. The next step in this phase is to develop the project charter, which is a plan. This plan specifies the boundaries and scope, goals, timeframe and the deliverables of the project. The goals of the project should be aligned strategic plan of the company. All of this definition of the project is in the form of a document which has to be improved formally before the start of the project. Who should define the problem related to organization, which has to be solved? If the organization is located in a low power distance country like Sweden or America, then any employee in the organization has the right to identify the problem. But in the countries with high power distance culture only the upper management has the right to define the problem; specifically it is the management of the department or area where the problem has occurred. The cultural dimension of uncertainty avoidance has a effect on the charter of the project. After the problem is defined, the next step is making the charter of the project. The culture with low uncertainty avoidance make the charter not so specifically, it would like any other project. But in the societies with high uncertainty avoidance, will make it with so many rules and regulations. Societies with feminine culture would make sure that everybody in the group has a full participation. Therefore we can conclude that in the defining phase of Six Sigma project, the national culture of the country has the moderating effect. We would develop our first proposition here as given below:

\section{Proposition no. 1: National culture moderates the defining phase of Six Sigma process}

Measure: Quality characteristics are determined at this stage of the Six Sigma methodology. Those quality characteristics or features are selected which emulate product improvements. Then a measurement system is developed, so that data could be collected based on those features. Next step is to develop a process map, which identify inputs for every process step referred by X. For each of these process steps designated by Xs, there is a corresponding output Y. The terminology of Six Sigma is represented by Xs and Ys. Xs represent not only the inputs but also the process which has to be done on that X. Each of those Xs and Ys statistically emulate the array of independent and dependent variables. The project's purpose is to improve the Ys. For the data collection in this perspective, the team members are designated and their roles of Six Sigma project team are defined, this part of the process is again affected by the national culture. In the societies with high power distance usually the higher management 
has the access to data but for the six sigma projects this access has to be loosening to everybody in the project, but for the low power distance societies it is not a problem. We offer the second proposition here as:

\section{Proposition no. 2: National culture moderates the measuring phase of Six Sigma process.}

Analyse: Once the data collection process is complete and the data is acquired, then the next step is to analyse the data. The purpose of this step is to present useful information that helps in modifying the process and thus solving the focussed problem. The tools of Quality management such as flow charts, Pareto charts, cause-and-effect diagrams, scatter diagrams and SPC charts are utilized in analysis. Purpose of this step is to pinpoint the root causes of the problem and then eliminate the problem. This Six Sigma phase has very less amount of interaction among team members so it is less vulnerable to the differences in national culture. But still statistical problem solving can have a little influence of the national culture. The societies with high uncertainty avoidance keep their tolerance limits of statistical processes at very low values. Societies with collectivist orientations get their analysis done at the group level. At this point we present our third proposition.

\section{Proposition no. 3: National culture moderates the analysis of the process of Six Sigma problem}

Improve: This phase has its focus on manipulating the Xs to enhance the performance considerably. But here the question is who is going to lead the process of improvement. In the cultures with collectivist orientation, it is in the domain of groups to take the responsibility of improving the process. Whereas in high power distance cultures, the owner of the process usually drives the improvement process. In cultures with a high level of uncertainty, the steps would be taken very cautiously to avoid the risks of getting into failures. In this respect the proposition 4 is offered.

\section{Proposition no 4: National culture moderates the improving process of six sigma problem}

Control: The last process in the Six Sigma project is the control phase. In this step the national culture affects the time horizon as well as the responsibility for sustainability. For instance the societies with short term orientations have their expectations up to a period of quarter of fiscal year, but for long term oriented societies this period may extend up to a whole year or more. In cultures with high power distance (PD) success of the project is wholly attributed to the owner/manager of the project whereas for low PD societies the appreciation is for the whole team. We offer the fifth proposition here:

\section{Proposition no. 5: National culture moderates the controlling process of six sigma problem.}

Solution: After the completion of the Six Sigma process the solution phase starts. This includes the documentation of the project's methodology as well as the results in a database, thus formally terminating the project. It also includes the recognition of contribution of the team members included in the project. The database becomes the common source through which knowledge is shared among the organization. The organizations which are knowledge based such as technology companies or the consulting firms, the database access is determined keeping in view of the cultural concerns. Collectivist cultures want to share more the information therefore they provide access to database organizationwide. The access to the database given by high power distance societies would be dependent on the hierarchical position of the member or employee.

\section{Conclusion}

Six Sigma has progressively developed into an effective improvement process which over the years has been applied in many countries and industries throughout the world. Through applying the six sigma methodology many companies from many countries have improved their performance. This methodology was originally developed and also refined in the US, so it is naturally adapted to the US culture. Its adoption and adaptation in other countries, specifically with very different cultures than the US has not been adequately researched. This study investigates into that, the methodology of Six Sigma does not adjust automatically into foreign cultures, as it is developed to be best suited to the cultural values, behaviours and expectations of the US culture. A conceptual model is proposed here, which by making use of the Hofstede's cultural dimensions prove that during the various phases of Six Sigma process, the potential cultural clashes may occur. Further research is obviously needed to further investigate into the 
influence of national culture on the phases of Six Sigma. Six Sigma can be affected by national culture in many ways and in cases of cultural clashes, can cause degradation of the quality.

\section{References}

Adler, N. J. (2002). International dimensions of organizational behavior (4th Ed.). Cincinnati, OH: SouthWestern Thomson Learning.

Anthony, J. \& Banuelas, R. (2002). Key Ingredients for the Effective Implementation of Six Sigma Program. Measuring Business Excellence, 6(4), 20-27.

Bertels, T. (2000). But we don't have processes! Six Sigma goes beyond manufacturing. Leadership Report, $3,1-5$.

Bigio, D., Edgeman, R. \& Ferlemen, T. (2004). Six Sigma availability management of information technology in the office of the chief technology officer of Washington, DC. Total Quality Management \& Business Excellence, 15(5), 679-688.

Binder, R. \& Lawrence, S. (1997). Can a manufacturing quality model work for software? IEEE Software, 14(5), 101-103.

Brun, A. (2010). Critical success factors of Six Sigma implementations in Italian companies. International Journal of Production Economics, 131, 158-164.

Coronado, R. \& Antony, J. (2002). Critical success factors for the successful implementation of Six Sigma projects in organizations. The TQM Magazine, 14(2), 92-99.

Crom, S. (2005). Using Six Sigma in Europe: A cross-cultural perspective. iSixSigma Europe, 2(2).

Dale, B. (2000). Marginalization of quality: Is there a case to answer? The TQM Magazine, 12, 266-274.

Dasgupta, T. (2003). Using the Six-Sigma metric to measure and improve performance of a supply chain. Total Quality Management \& Business Excellence, 14(3), 355-366.

De Brantes, R. \& Galvin, R. (2001). Creating, connecting and supporting active consumers. International Journal of Medical Marketing, 2(1), 73-81.

Does, R., Van Den Heuvel, E., De Mast, J. \& Bisgaard, S. (2002). Comparing nonmanufacturing with traditional applications of Six Sigma. Quality Engineering, 15(1), 177-183.

Eckes, G. (2000). The Six Sigma revolution. New York: John Wiley \& Sons.

Frank, S. (2003). Applying Six Sigma to revenue and pricing management. Journal of Revenue \& Pricing Management, 2(3), 245-254.

Gnibus, R. (2000). Six Sigma's missing link. Quality Progress, 33(11), 77-81.

Gupta, P. (2005). The Six Sigma performance handbook. New York: McGraw-Hill.

Hall, E.T. \& Hall, M. R. (1990). Understanding cultural differences: Germans, French and Americans. Yarmouth, ME: Intercultural Press, Inc.

Harry, M. (2000). A new definition aims to connect quality with financial performance. Quality Progress, 33(1), 48-53.

Harry, M. \& Schroeder, R. (2000). Six Sigma: The breakthrough management strategy revolutionizing the world's top corporations. New York, US: Currency Publishers.

Henderson, K. \& Evans, J. (2000). Successful implementation of Six Sigma: Benchmarking General Electric Company. Benchmarking, 7(4), 260-282.

Hendricks, C. \& Kelbaugh, R. (1998). Implementation of Six Sigma at GE. Journal for Quality and Participation, 21(4), 48-53.

Hendry, L. \& Nonthaleerak, P. (2005). Six Sigma: Literature review and key future research areas. Working Paper. Department of Management Science, Lancaster University, UK. Retrieved September 23, 2005, from http://www.lums.lancs.ac.uk/publications/viewpdf/002475/

Hofstede, G. (1980). Culture's consequences: International differences in work-related values. Beverly Hills, CA: Sage.

Hofstede, G. (1993). Cultural constraints in management theories. Academy of Management Executive, 7(1), 81-94.

Hofstede, G. (1994). Management scientists are human. Management Science, 40(1), 4-13.

Hofstede, G. (1997). Cultures and organizations: Software of the mind. New York: McGraw-Hill.

Hofstede, G. \& Hofstede, G. J. (2005). Cultures and organizations: Software of the mind (revised and expanded 2nd ed.). New York: McGraw-Hill.

Hong, G. \& Goh, T. (2003). Six Sigma in software quality. The TQM Magazine, 15(6), 364-373.

Hutchins, G. (2000). The branding of Six Sigma. Quality Progress, 33(9), 120-122.

Kaufmann, U. H. (2000). Six Sigma is in the bloodstream when Leadership Report, Spring, 3-4.

Kilbey, G. (2003). Six Sigma. BpFS, 117(4), 18-20. 
Lanyon, S. (2003). At Ratheon Six Sigma works, too, to improve HR management processes. Journal of Organizational Excellence, 22(4), 29-42.

Lipscomb, B. \& Lewis, A. (2004). The principles of Six Sigma: Building a quality claims management program. Risk Management, 51, 30-34.

Lee, T., Wong, W., \& Yeung, K. (2011). Developing a readiness self-assessment model (RSM) for Six Sigma for China enterprises. International Journal of Quality \& Reliability Management, 28(2), 169-194.

McAdam, R. \& Lafferty, B. (2004). A multilevel case study critique of Six Sigma: Statistical control or strategic change? International Journal of Operations \& Production Management, 24(5), 530-549.

McCarty, T., Daniels, L., Bremer, M. \& Gupta, P. (2005). The Six Sigma black belt handbook. New York: McGraw-Hill.

Newman, K. L. \& Nollen, S. D. (1996). Culture and congruence: The fit between managerial practices and national culture. Journal of International Business Studies, 27(4), 753-779.

Niemes, J. (1999). Taking sales success to new heights with Six Sigma. National Productivity Review, 18, 37-42.

Pande, P., Neuman, R. \& Cavanagh, R. (2000). The Six Sigma way: How GE, Motorola and other top companies are honing their performance. New York: McGraw-Hill.

Pisani, M. J. (2000). An American management training model in a Latin American context: Some implications for international business consultants. Journal of Teaching in International Business, 12(1), 23-39.

Pylipow, R. (2001). Can it be this easy? Quality Progress, 34(7), 139-141.

Revelle, J. (2004). Six Sigma. Professional Safety, 49(10), 38-47.

Rucker, R. (2000). Citibank increases customer loyalty with defect-free processes. Journal of Quality \& Participation, 23(4), 32-37.

Snee, R. (2001). Make the view worth the climb. Quality Progress, 34(11), 58-61.

Sodhi, M. S. \& Sodhi, N. S. (2005). Six Sigma pricing. Harvard Business Review, 83(5), 135-142.

Watson, G. (2000). Toward central tendency on Six Sigma. Quality Progress, 33(7), 16-17.

White, E. (2005). Rethinking quality improvement. Wall Street Journal, 2, 19, B3. 